\title{
Improvement of the Computing and Geoinformation System in terms of creating maps with detailed settlements
}

\author{
Ivan L. Trofimov ${ }^{1, *}$, Leonid N. Trofimov ${ }^{1}$ \\ ${ }^{1}$ Melentiev Energy Systems Institute of Siberian Branch of the Russian Academy of Sciences, Electric Power Systems Department, \\ 664033, 130, Lermontova Str., Irkutsk, Russia
}

\begin{abstract}
The article is devoted to refinement (improvement) of the Computing and geoinformation System to create maps with detailed settlements in different regions for visual analyzing their energy infrastructure. The problem of visualization and systematization of cartographic data is being solved. An interface has been developed for constructing interactive maps and navigation in any section of the world atlas. The technology of graphical and cartographic data visualization using the concept of atlas cartography is developed. This concept implies the display of an interactive geographic map of any region of the world at any scale, created in the unified structure and coordinate system, with the layers of raster and vector data and the energy infrastructure applied on it. The data overlaid on the map can be energy facilities (power plants), electric power systems, and data obtained as the results of calculations on the optimization model (not described in this paper).
\end{abstract}

\section{Introduction}

The authors have developed the software tool (Computing \& Geoinformation System "CGIS") for complex analysis of energy infrastructure and studying interstate power grid expansion in various world regions.

An object database has been developed, which contains contour maps of all world countries with their administrative divisions [1-3]. The database contains information about all major power plants in the world, their geographic coordinates, technical and economic parameters, and more. The CGIS interface allows us to create maps of any territory, including several countries or their regions at any scale.

The CGIS implements the construction of hybrid maps containing vector and raster layers and the energy infrastructure of the selected territory or region applied to them. Practical application of atlases built-in CGIS is used in our institute to study and visualize the region's energy infrastructure and plot the solving results of the optimization model ORIRES on a map of the selected territory. ORIRES model reflects the optimal regimes of the interconnected power systems in different scenarios [4-6]. The visual location of energy objects and their consumers gives more complete data for qualitative analysis and study of the energy infrastructure of the different regions.

In 2020, the possibilities of geoinformation mapping of various regions in the CGIS were significantly expanded (improved):

- There is a new possibility of mapping settlements in the studied region. Most data sources with data about settlements, as a rule, contain only their geographical coordinates (one point on the map). The CGIS implements a new technology of mapping settlements in the polygon form, based on satellite images of the Yandex Maps. This makes it possible to generate more accurate (precise) maps of various regions for a qualitative assessment of their energy infrastructure.

- Specialized algorithms for assigning (belonging) energy objects to different administrative regions, algorithms for determining the geometric areas of polygons have been implemented.

- Due to the information on the exact location and types of energy facilities near settlements in the studied region, it is possible to carry out various analyzes of the energy infrastructure.

The goal: improvement of the software (CGIS), which allows to research prospective interstate power grids expansion and solve a wide range of problems associated with a comprehensive study of energy infrastructure in the studied regions. The software that includes both a graphic and an informational-analytical part with information about the studied regions' energy infrastructure and a computing part for an optimization model has no analogues in Russia and the world.

\section{Information base (data sources)}

Official internet sources of data about energy facilities in various countries have limited or paid access. Government databases are not available, and public

* Corresponding author: t_john88@isem.irk.ru 
information is generally non-structured for automated machine processing.

We have developed a semi-automated method (algorithm) to acquire non-uniform information from various sources and its allocation into the object structure with its subsequent verification and analysis.

The first primary source of information containing data on thousands of power plants around the world is DBpedia.org [7]. The information is stored in the form of ontologies and can be loaded in RDF/XML format. DBpedia data are information boxes taken from Wiki and transferred to RDF. RDF syntax provides machinereadable resource information. We have developed a mini-scanner software and downloaded several thousand power plants of the world into our database, figure 1 . However, the first analysis of this data showed that the information is incomplete and needed to be verified.

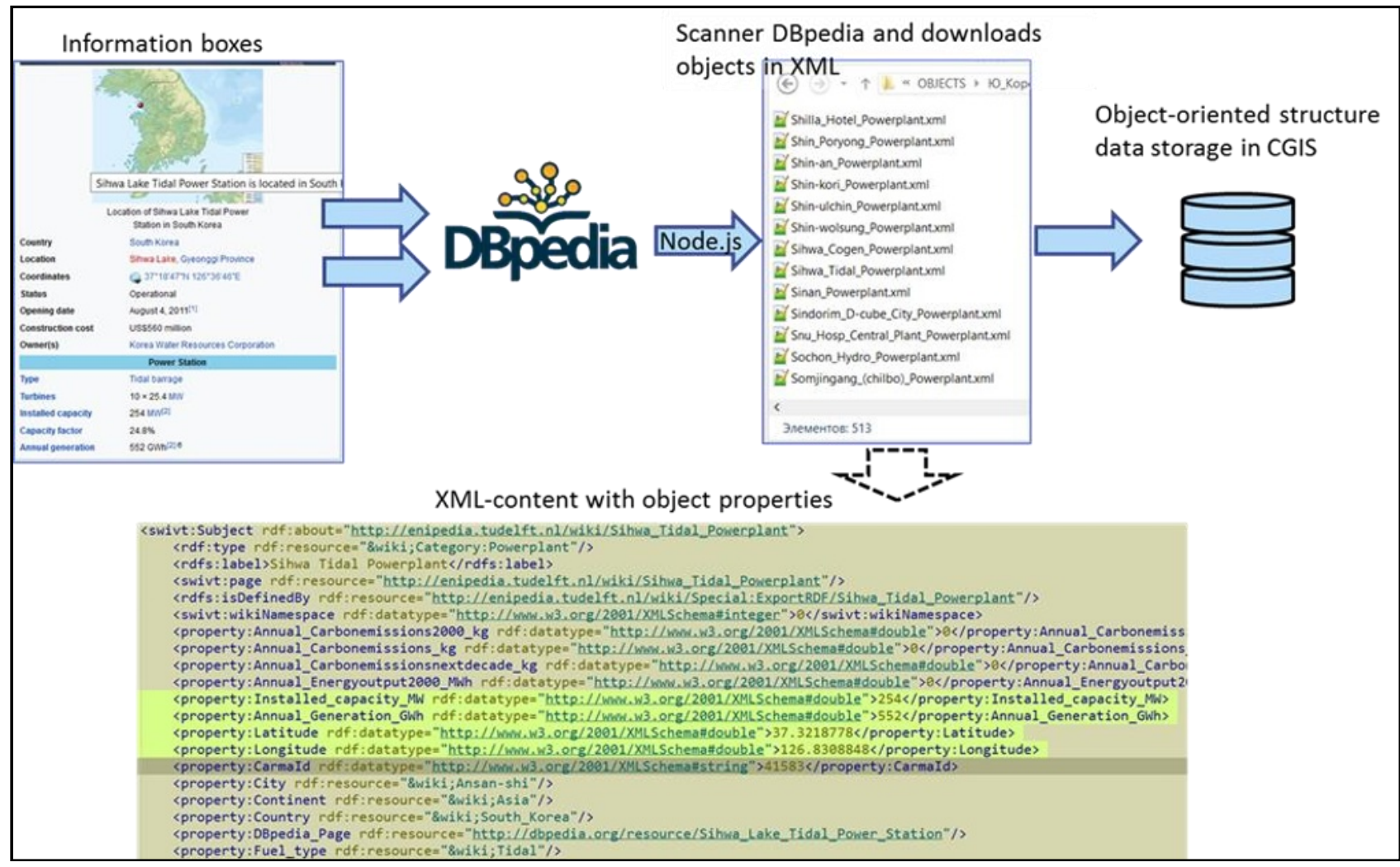

Fig. 1. Scheme (an algorithm) for downloading and transforming data from DBpedia.

The following primary source is World Resource Institute [8], which contains a complete database about energy entities in the world. This data source has many social, economic, and finance data. There are many datasets: climate watch, global power plant database, forest landscapes, protected areas, etc.

It provides a visual online tool, but without the possibility of any additions or changes. The most helpful dataset is the Global Power Plant Database. The Global
Power Plant Database is a comprehensive, open-source database of power plants around the world. It covers approximately 30,000 power plants from 164 countries and can be visualized on Resource Watch.

However, the only visual tool is not enough for our research, so we have downloaded this dataset into our object structure. CSV format is too close to the file structure of our database, figure 2 .

\begin{tabular}{|c|c|c|c|c|c|c|c|c|c|c|}
\hline \multicolumn{2}{|r|}{ A1 } & \multicolumn{2}{|c|}{ 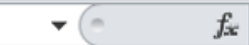 } & \multicolumn{7}{|c|}{ country,country_long,name,gppd_idnr,capacity_mw,latitude,longitude,pr } \\
\hline$\Delta$ & A & $B$ & C & & & & & & & \\
\hline 1 & \multicolumn{10}{|c|}{ country,c_cuntry_long,name,gppd_idnr,capacity_mw,latitude,longitude,prir } \\
\hline 2 & \multicolumn{10}{|c|}{ AFG,Afghanistan,Kajaki Hydroelectric Power Plant Afghanistan,GEODB0040538,33.0,32.3220,65.1190,Hydro, } \\
\hline 3 & \multicolumn{10}{|c|}{ AFG,Afghanistan,Mahipar Hydroelectric Power Plant Afghanistan,GEODB0040541,66.0,34.5560,69.4787, Hyd } \\
\hline 4 & \multicolumn{10}{|c|}{ AFG,Afghanistan,Naghlu Dam Hydroelectric Power Plant Afghanistan,GEODB0040534,100.0,34.6410,69.7170 } \\
\hline 5 & \multicolumn{10}{|c|}{ AFG,Afghanistan,Nangarhar (Darunta) Hydroelectric Power Plant Afghanistan,GEODB0040536,11.55,34.4847 } \\
\hline 6 & \multicolumn{10}{|c|}{ AFG,Afghanistan,Northwest Kabul Power Plant Afghanistan,GEODB0040540,42.0,34.5638,69.1134,Gas ${ }_{m, \ldots,}, \mathrm{GE}$} \\
\hline
\end{tabular}

Fig. 2. CSV-file content with geo-coordinates and energy parameters of the power plants.

In addition, we needed the contour maps of any regions in the world. The DIVA-GIS is an excellent resource with Free Spatial Data in the Shape format [9]. Free Spatial Data (Shape File. SHP) provides us with 
the country-level data for any country in the world: administrative boundaries, roads, railroads, altitude, land cover, population density. We have processed this data and constructed maps of about 200 countries in the world, divided by administrative boundaries, with their names. Owing to this work, one can navigate through the list of countries with already prepared maps in the CGIS, like a world interactive atlas [10]. This database allows us to create maps of any regions for research effectively. Any area/region on the world map can be marked with a rectangle in the CGIS interface and stored in a temporary folder in our database for further work. Then combined raster and vector layers are created for it. We can overlay the layers of texts, energy data, and geospatial objects on this map.
The CGIS implements the construction of hybrid maps that contain vector and raster map layers and the energy infrastructure applied to them. Some technical features and problems related to the technology of displaying maps in various projections can be found in the paper of Trofimov I. and Trofimov L., "Aspects of Atlas Mapping for Analysis of Energy Infrastructure in Different Regions" [11]. The CGIS uses Yandex Maps as raster images in the Mercator elliptical projection (EPSG: 3395 - WGS 84 / World Mercator) [12]. This year we have started new basic research of prospective interstate power grid expansion in Central Asia \& the Caucasus. As an example in this paper, the construction of the Armenia map is considered, figure 3.

\section{Technology of mapping settlements}

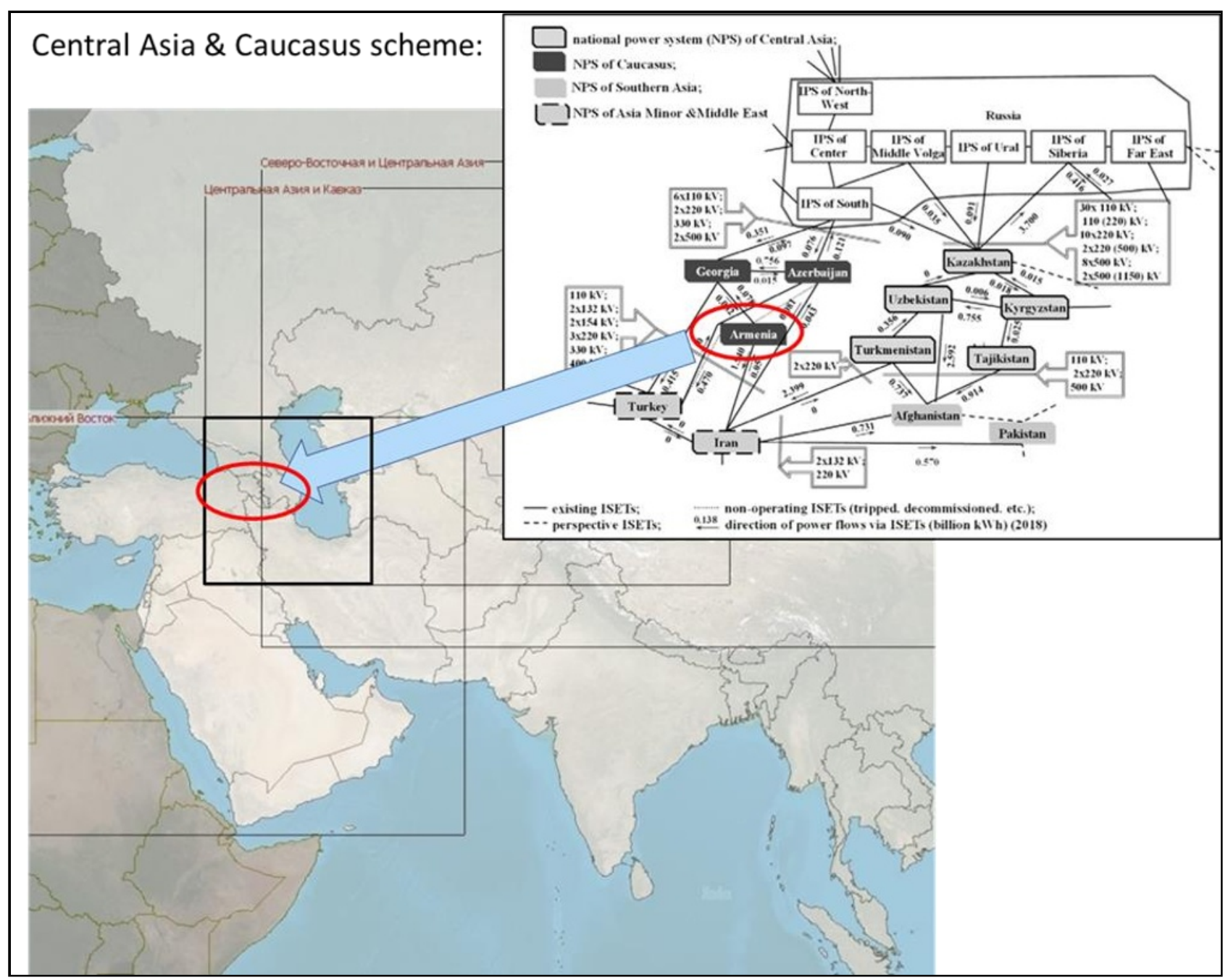

Fig. 3. Map scaling of the Central Asia and Caucasus region in the CGIS cartographic interface.

In 2020, we constructed contour maps with administrative boundaries of any country in the world, with their names in Russian and English. This year (2021), we have implemented a new mapping settlement technology in the polygon form. This makes it possible to generate more accurate (precise) maps of different regions to analyze their energy infrastructure comprehensively.

The problem is that the standard representation of data on settlements is implemented in the only form of coordinate points. Therefore, it is impossible to determine the scale of settlements. 
A comprehensive analysis of the energy infrastructure in the studied region may include:

- The problem of assessing environmental risks from existing and planned capacities (power plants).

- Assessment of the electric power demand construction of new capacities (power plants).

- The problem of determining the population density that may affect the prospective level of electricity consumption.
- Assessment of the efficiency of prospective interstate power interconnections (interstate electric ties) and other problems.

Therefore, a more detailed representation of the boundaries and scale of settlements in the studied regions is required and the definition of large regional centres, figure 4 .

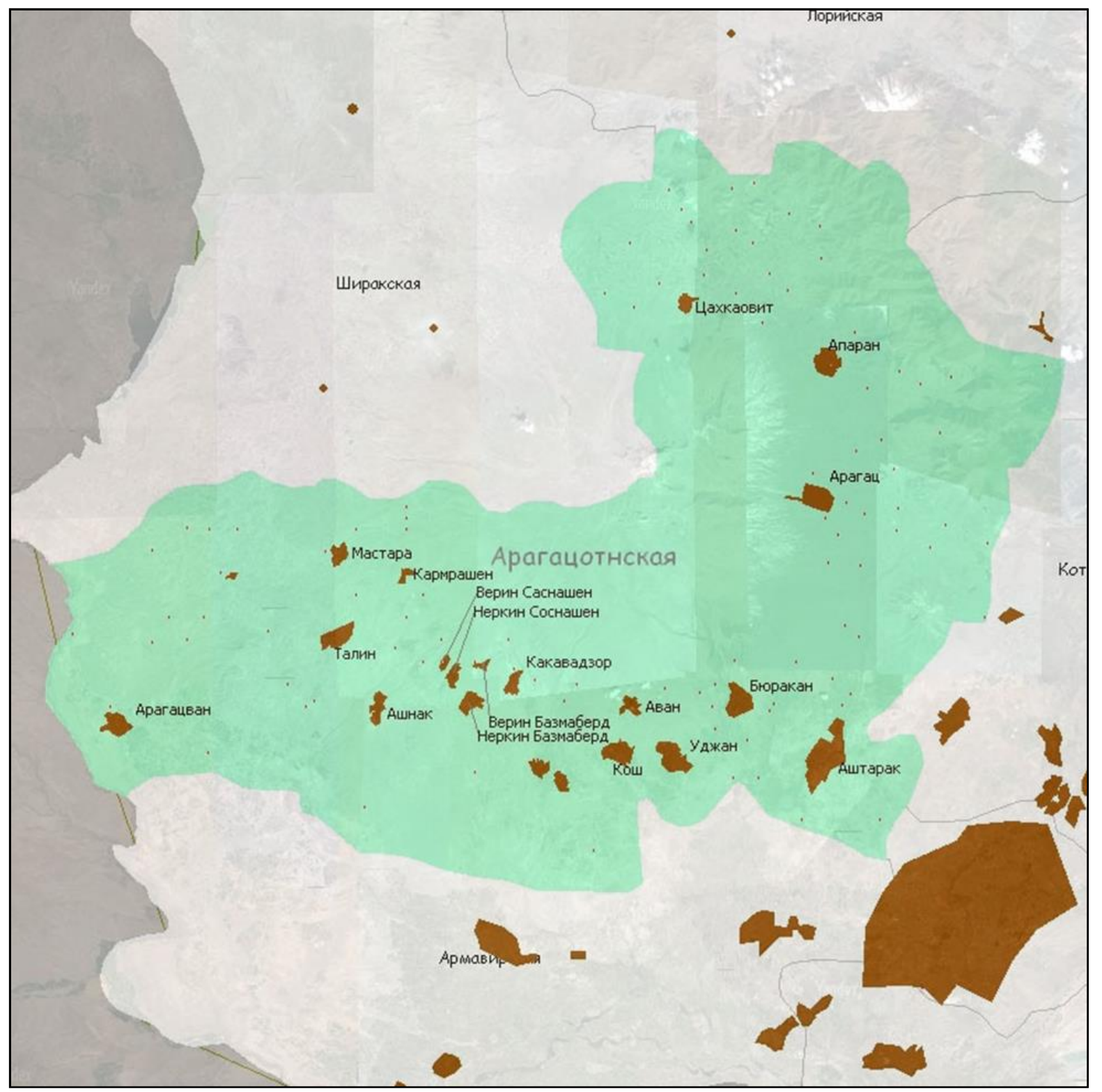

Fig. 4. Large regional centers in the Aragaconskaya oblast of Armenia.

After creating such maps, we can draw the electrical schemes of this region, the location of power plants, and other information from the CGIS database.

Below is the technology for constructing polygons using the example of the Ashnak city:

1. Zooming the required region from the satellite map in the CGIS cartographic interface.
2. Selecting a settlement (indicating name in the database)

3. Drawing the polygon around the settlement borders by using special instruments, figure 5 . 


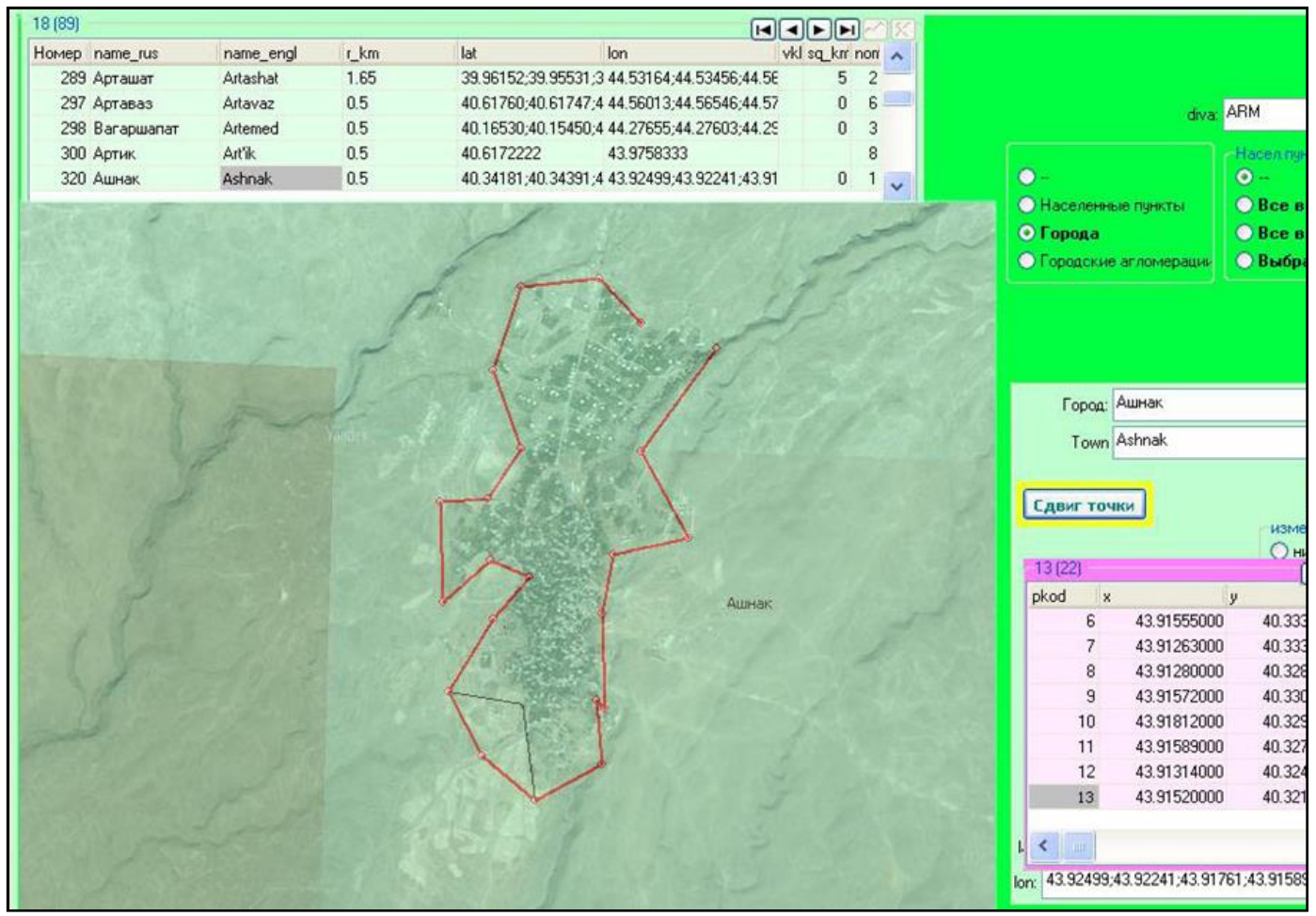

Fig. 5. Instruments for drawing a polygon around the settlement in the CGIS cartographic interface.

4. These instruments allow one to change some points of the polygon if it is needed.

5. Save the new settlement polygon.
In the next step, we can draw an additional layer with the existing power plants for visual analysis of the energy infrastructure in the studied region, figure 6.

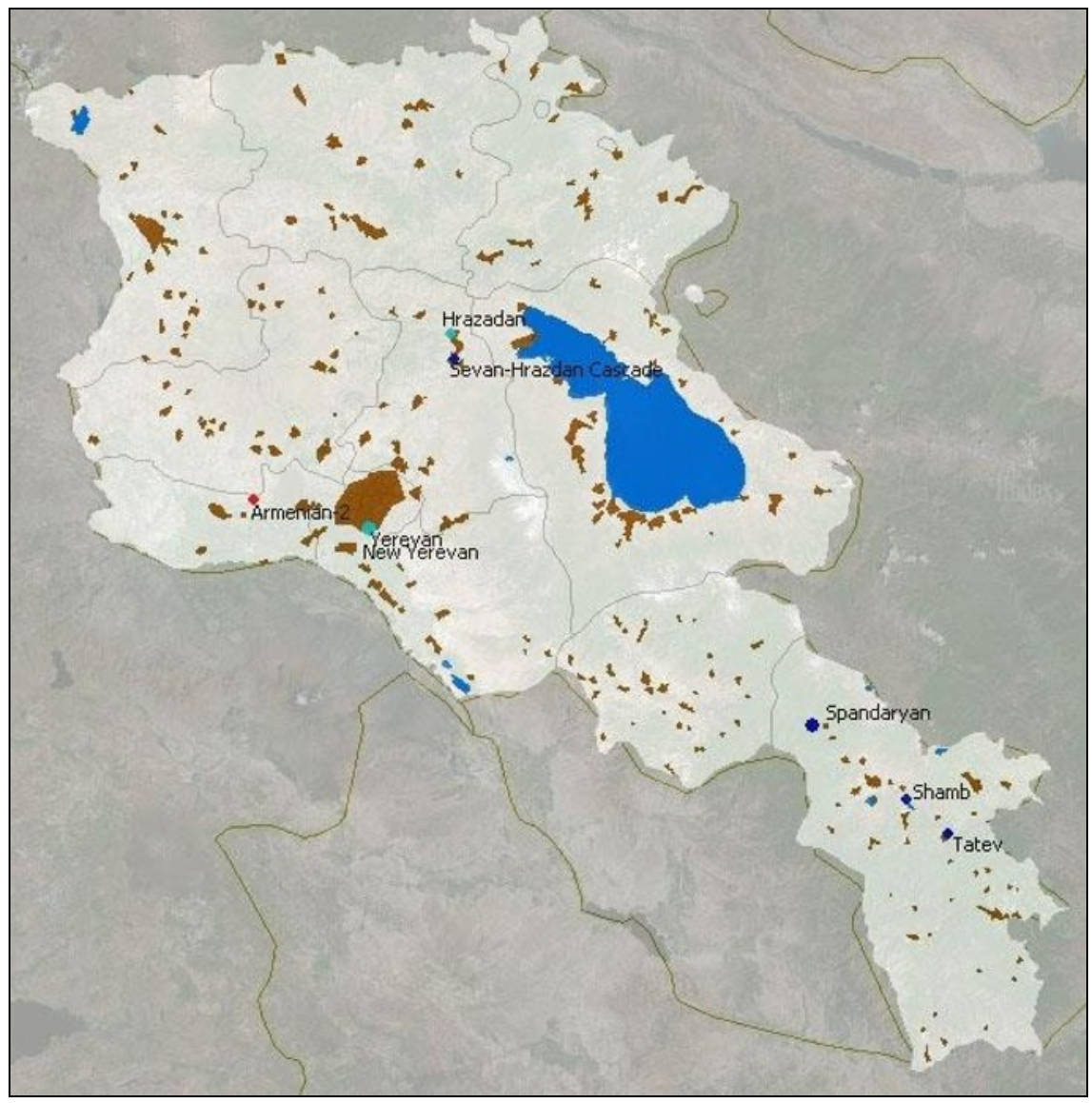

Fig. 6. Ready map of Armenia. 
In this map, the largest settlements of Armenia and power plants from the database are shown:

- Armenian-2 (Nuclear power plant)

- Yerevan (Gas power plant)

- New Yerevan (Gas power plant)

- Hrazdan (Gas power plant)

- Sevan-Hrazdan Cascade (Hydropower plant)

- Spandaryan (Hydropower plant)

- Shamb (Hydropower plant)

- Tatev (Hydropower plant)

All other maps in the studied region are built with the same technology.

\section{Conclusions}

Our research has required the analysis and processing of a huge amount of data. Without problem-oriented software (the CGIS) and a database, the research may take much time.

We have developed a new software tool to analyze and process a large volume of energy data. The main functional components (program modules) of the CGIS have been developed.

The technology of creating maps with detailed settlements in different regions for analyzing their energy infrastructure has been implemented. The visual location of energy entities and energy consumers gives complete information for qualitative analysis and study of energy infrastructure in different regions.

The CGIS is universal software that includes both a graphic and an informational-analytical part with visual information about the energy infrastructure of the studied regions, as well as a computing part for working with an optimization model, has no analogs in Russia and the world.

The research was carried out under State Assignment Project (no. FWEU-2021-0001) of the Fundamental Research Program of the Russian Federation 2021-2025.

\section{References}

1. I. L. Trofimov, et al., "The computing and information system for research of prospective electric power grids expansion," Yugosl. J. Oper. Res., 29, 4 (2019)

DOI: http://dx.doi.org/10.2298/YJOR181115021T

2. I. L. Trofimov, et al., "Data processing and optimization system to study prospective interstate power interconnections," in 10th International Conf. on Asian Energy Cooperation, E3S Web Conf., 27 (2017) DOI http://dx.doi.org/10.1051/e3sconf/20182701007

3. I. L. Trofimov, et al., "The Computing and Information System for Study of Scenarios for Interstate Power Grid Expansion," in IEEE 2019 16th International Conf. on Electrical Engineering / Electronics, Computer, Telecommunications and Information Technology (ECTI-CON), Pattaya, Chonburi, Thailand, (2019) DOI:http://dx.doi.org/10.1109/ECTICON47248.2019.8955179
4. L. S. Belyaev, et al., "The effectiveness of interstate electric ties" (Novosibirsk: Nauka, 2008) [in Russian]

5. L. S. Belyaev, et al., "Studies of interstate electric ties in Northeast Asia," International J. of Global Energy Issues, 17, 3 (2002)

6. S. V. Podkovalnikov, et al., "Justification of Effectiveness of International Power Interconnections with Separation of Effects between Participants," Automation and remote control, 10 (2018) DOI: http://dx.doi.org/10.1134/S0005117918100028

7. DBpedia. Global and Unified Access to Knowledge Graphs. Available at: https://www.dbpedia.org, [accessed: 10 March 2021].

8. World Resources Institute. Available at: https://www.wri.org/ [accessed: 12 March 2021].

9. DIVA-GIS. Available at: https://www.divagis.org/, [accessed: 13 April 2020].

10. O. Zolotova, E. Skupinova, D. Bondarenko, V. Drobyshev, "GIS and Atlas mapping," ArcReview Electronic Journal, 1, 44 (2008) [In Russian]

11. I. L. Trofimov, L. N. Trofimov, "Aspects of Atlas Mapping for Analysis of Energy Infrastructure in Different Regions," Energy Systems Research, 4, 1 (2021) DOI: http://dx.doi.org/10.38028/esr.2021.01.0006

12. World Geodetic System Projections. Available at: https://gisgeography.com/ellipsoid-oblate-spheroidearth/, [accessed: 10 February 2020] 